\title{
Cultural Sexism Moderates Efficacy of Psychotherapy: \\ Results from a Spatial Meta-Analysis
}

\author{
Maggi A. Price, $\mathrm{PhD}$ \\ School of Social Work, Boston College \\ Department of Psychology, Harvard University
}

Sarah McKetta, MSc

Department of Epidemiology, Columbia University Mailman School of Health

John R. Weisz, PhD

Department of Psychology, Harvard University

Jessie V. Ford, PhD

Department of Sociomedical Sciences, Columbia University Mailman School of Health

Micah R. Lattanner, PhD

Department of Epidemiology, Columbia University Mailman School of Health

Hilary Skov, BA

Department of Psychology, Tulane University

Elizabeth Wolock, BA

Department of Clinical and Health Psychology, University of Florida

Mark L. Hatzenbuehler, PhD

Department of Psychology, Harvard University

Trial registration: PROSPERO identifier CRD42017072759

\section{Draft version 3 (4-13-2021). Please do not copy or cite without the authors' permission.}

Accepted for publication in Clinical Psychology: Science and Practice on April 11, 2021

Price, M., McKetta, S., Weisz, J., Ford, J., Lattanner, M., Skov, H., Wolock, E., \&

Hatzenbuehler, M. (in press). Cultural sexism moderates efficacy of psychological therapy for girls: Results from a spatial meta-analysis. Clinical Psychology: Science and Practice 


\begin{abstract}
We examined whether cultural sexism (county- and state-level gender attitudes) moderates the efficacy of psychotherapies by re-analyzing data from a previous meta-analysis of randomized controlled trials of youth psychotherapy for the most commonly targeted problems (depression, anxiety, conduct, attention-deficit hyperactivity disorder; 2,698 effect sizes (ESs); 314 studies; $N=19,739$; ages 4-18). Higher cultural sexism was associated with lower ESs for studies with $\geq 50 \%$ girls; this association became stronger as the proportion of girls in the samples increased. Cultural sexism was unrelated to ESs for studies with $>50 \%$ boys. An interaction between state- and county-level sexism revealed that psychotherapies were most beneficial when they were conducted in states and counties with the lowest cultural sexism. Thus, the context in which psychotherapies are delivered is associated with psychotherapy efficacy for girls.
\end{abstract}

Keywords: cultural sexism, psychotherapy, treatment effectiveness, gender, children and adolescents

Public Significance Statement: This spatial meta-analysis found that psychotherapy randomized controlled trials with samples comprised of a majority of girls were significantly less effective in states with higher vs. lower levels of cultural sexism. These findings suggest that examining the social contexts in which psychotherapy interventions are delivered may yield new insights into who benefits most (and least) from mental health treatments. 


\section{Cultural Sexism Moderates Efficacy of Psychotherapy: Results from a Spatial Meta-Analysis}

One of the most pressing issues in psychotherapy research is evaluating treatment effect heterogeneity (Reardon \& Stuart, 2017) — that is, identifying for whom, and under what conditions, mental health is improved by the interventions received, as well as which dimensions of mental health are improved by which interventions. To date, studies have focused almost exclusively on the identification of individual (e.g., gender, race) and study-specific (e.g., treatment modality) characteristics that moderate intervention efficacy. Consequently, it remains largely unknown whether contextual features of the broader social environment in which therapies occur are associated with intervention impact (Johnson et al., 2017). The lack of research on contextual mechanisms that may affect therapy response is striking, given the robust literature that social/contextual factors-including income inequality (Pickett et al., 2006), social capital (Flores et al., 2017), and neighborhood violence (Fowler et al., 2009), among many others-shape mental health. The current paper seeks to address this gap in the literature by examining whether one potential contextual risk factor for mental health—cultural sexism—is associated with reduced intervention efficacy among girls receiving psychotherapy. To address this research question, we draw on and integrate several relevant literatures from psychology, sociology, and public health—including gender as a social structure (Risman, 2004), feminist psychology (Brown, 2018), and macro-level stigma (Hatzenbuehler, 2016) —and utilize a recent innovation in studying contextual moderators of intervention efficacy: spatial meta-analysis (Johnson et al., 2017).

\section{Psychopathology and Psychotherapy among Girls}


Girls and women evidence higher rates of depression and anxiety relative to boys and men. Meta-analyses suggest that throughout adolescence and adulthood, girls are more likely than boys to experience depression (Salk et al., 2017; Twenge \& Nolen-Hoeksema, 2002), with adolescent girls and women being twice as likely to be diagnosed with major depression (Merikangas et al., 2011). Similar gender differences with respect to magnitude and chronicity have been found in studies of anxiety, with these disparities emerging even earlier (i.e., around age 6; Kessler et al., 2005). Although boys are significantly more likely than girls to be diagnosed with externalizing disorders (e.g., conduct disorder, attention deficit hyperactivity disorder [ADHD]; Merikangas et al., 2011), this disparity is narrowing (Moffitt, 2003).

Though studies of nationally-representative samples of youth suggest that boys are more likely to use therapy compared to girls (Mennies et al., 2021; Simon et al., 2015; Simpson et al., 2008), research on mental health treatment utilization with adults is mixed (Gagne et al., 2014), with some studies finding higher use among women (e.g., Albizu-Garcia et al., 2001), and others indicating higher use among men (e.g., Rhodes et al., 2006). Of note, boys' willingness to use or seek out mental health services is lower than that of girls (Chandra \& Minkovitz, 2006; Sen, 2004) and is associated with conformity to traditional masculine norms (e.g., stigma surrounding help-seeking; Chandra \& Minkovitz, 2006; Seidler et al., 2016). Despite potential differences in treatment utilization, outcomes do not systematically differ across girls and boys (Nilsen et al., 2013), though exceptions exist (e.g., Watson \& Nathan, 2008).

There is a large literature on the causes of the gender disparity in internalizing psychopathology, with explanations emphasizing the multilevel interplay of biological, psychological, social, and macro-level (e.g., structural and cultural) factors (for a review, see Hatzenbuehler \& McLaughlin, 2017). While empirical research has largely focused on 
identifying individual and interpersonal factors, feminist psychotherapy has long asserted that contextual factors related to gender and gender inequality_including sex roles, gender socialization, and the stigmatization of girls and women - contribute to psychological difficulties in girls and women (Miller, 1976). In locating the causes of mental health problems in the larger social context, feminist psychotherapists therefore emphasize treatment components such as consciousness-raising, gender-role analysis, and social activism (Israeli \& Santor, 2000). Feminist scholars have proposed models of feminist psychotherapy for girls (e.g., Multicultural Feminist Therapy, a gender- and culturally-affirming practice that centers the strengths and needs of girls and women of Color; Bryant-Davis, 2019), and research supporting feminist therapies (e.g., Relational Cultural Therapy; Oakley et al., 2013) is small but growing (Conlin, 2017; Gorey et al., 2003). The dearth of empirical studies on feminist psychotherapy contributes to its relative absence in the evidence-based practice discourse and core curricula of therapist training programs (Brown, 2006). Accordingly, it may be uncommon for sexism to be addressed in psychotherapy with girls, and that may hamper treatment efficacy for girls experiencing high cultural sexism.

\section{Gender as a Social Structure}

The theoretical arguments made in feminist psychotherapy are echoed in the sociological literature on gender as a social structure. In her seminal theory, Risman (2004) articulates the importance of an integrative, multi-level approach to the study of gender and sexism, with an explicit acknowledgment that individual, interactional, and macro levels are equally integral and complementary features of a larger social stratification system. Accordingly, gender inequality is

produced at each level: through the development of gendered selves (the individual level); during interactions where boys/men and girls/women face distinct expectations, even when occupying 
similar status positions (the interactional level); and in institutional domains where resources and opportunities are distributed unevenly based on gender (the macro level).

In a recent revision to this theory, Risman (2017) stressed the importance of differentiating between cultural and material dimensions at each level of the gender structure. Cultural dimensions are conceptualized as hegemonic and ideological beliefs (macro level), interpersonal expectations and stereotypes (interactional level), and internalized gendered selves (individual level). Material dimensions, in contrast, include the distribution of resources (macro level), access to social networks (interactional level), and the physical body (individual level).

\section{Macro-Level Material Sexism}

Research on the physical and mental health consequences of macro-level sexism has focused largely on the material (vs. cultural) dimensions of the gender structure. These studies have leveraged variation in macro-level sexism across geographic units of analysis (e.g., countries, states, counties) using a variety of indicators of material sexism — which frequently include indices of women's economic, political, and reproductive autonomy, both as absolute (e.g., the percentage of women living below the poverty line) and relative (e.g., the ratio of women to men living below the poverty line) measures. This work has shown that women living in U.S. states with relatively higher macro-level material sexism-i.e., with relatively higher rates of women's poverty, higher wage gaps, fewer legal protections, and less female representation in state government - are more likely to experience intimate partner violence, poor self-rated health, more chronic health conditions, poor physical functioning, and premature mortality (for a review, see King et al., 2020). County-level variation in macro-level material sexism in the U.S. has similarly been linked to differences in risk for female homicide (Vieraitis et al., 2016), child and infant homicide (Hunnicutt, 2007), and intimate partner violence 
(Gillespie \& Reckdenwald, 2017). Considerable effort has been made in these studies to rule out alternative explanations by controlling for other macro-level factors (e.g., area-level income inequality) and individual-level factors (e.g., demographics, marriage status, education status) that both vary geographically and influence health. Nevertheless, these findings are associational and thus it is possible that other confounding variables are responsible for these observed effects.

Regarding mental health specifically, two studies have found that women residing in states with higher levels of macro-level material sexism—-measured using four composite indices representing employment and earnings, political participation (e.g., women's voter turnout and representation in government), economic autonomy (e.g., women's small business ownership), and reproductive rights — had higher rates of any mood disorder, depressive symptoms, major depression, and post-traumatic stress disorder (Chen et al., 2005; McLaughlin et al., 2011). While relatively less attention has been paid to the relationship between macro-level material sexism and girls' health, one study found that higher state-level sexism (measured using the same four indices as above) was related to higher rates of teen pregnancy (Koenen et al., 2006).

\section{Macro-Level Stigma and Mental Health}

This work has provided important advancements in understanding how the material dimensions that underlie macro-level sexism increase risk for poor outcomes among women, including psychopathology. Yet, there is a dearth of research focusing specifically on the mental health consequences of cultural dimensions of macro-level sexism-operationalized as ideological beliefs and gender norms_-despite calls for this type of work (Risman, 2017; Salk et al., 2017). There is, however, an emerging body of empirical evidence that macro-level stigma, as measured via community-level ideologies and norms, can affect the mental health of lowstatus and marginalized groups (for reviews, see Hatzenbuehler, 2016; 2017). In these studies, 
individuals' attitudes (both implicit and explicit) related to particular stigmatized groups are aggregated to the community level—defined at various geographic scales (e.g., counties, states) - such that the level of stigma can be compared across communities. This approach of aggregating individual responses to create measures of macro-level prejudice reflects recent conceptualizations positing that regional bias may not simply reflect the aggregate of individual biases, but also shape social structures (e.g., laws, institutions) in ways that recursively influence the attitudes of residents in that region (e.g., Payne et al., 2017). Aggregated social norms have been used in previous research to measure macro-level stigma across a range of groups, including Black people (e.g., Leitner et al., 2016), immigrants (e.g., Morey et al., 2017), lesbian, gay, and bisexual (LGB) populations (e.g., Hatzenbuehler et al., 2017), individuals with serious mental health problems (e.g., Evans-Lacko et al., 2012), and individuals living with HIV/AIDS (e.g., Miller et al., 2011; 2016).

This work has shown that macro-level stigma is associated with numerous adverse psychosocial and health outcomes among the stigmatized, including self-stigma (Evans-Lacko et al., 2012), disclosure concerns (Miller et al., 2011), symptoms of psychological distress (Miller et al., 2016), hypervigilance and hopelessness (Russell \& Richards, 2003), perceived stress (Rostosky et al., 2009), poor self-rated health (Hatzenbuehler et al., 2017), and even shortened lifespans (Leitner et al., 2016). For instance, in one study, researchers measured macro-level stigma using aggregated data on public attitudes about people with mental health problems from 14 European countries. Among people diagnosed with serious mental health problems, those living in countries with lower levels of stigma related to mental health problems reported lower rates of self-stigma and of perceived discrimination than those in countries with higher stigma (Evans-Lacko et al., 2012). In another study, researchers measured macro-level stigma by 
collecting data on the share of votes for (or against) same-sex marriage. LGB people reported worse life satisfaction, lower social support, and poorer mental health in areas with higher (vs. lower) shares of votes against same-sex marriage (Perales \& Todd, 2018).

\section{Spatio-Temporal Meta-Analyses}

Thus, emerging evidence indicates that macro-level stigma, measured via aggregated norms and ideologies, can negatively affect the mental health of low-status and marginalized groups. In the current study, we examine another potential way in which macro-level stigma and prejudice, as it specifically relates to sex/gender (referred to as cultural sexism, herein), may adversely affect mental health — namely, through undermining the efficacy of psychotherapy for girls. Addressing this research question is methodologically challenging, however, because most therapy studies are conducted in only one, or a few, communities. Limited variation in the social contexts of most studies precludes sensitive tests of whether contextual factors, such as cultural sexism, moderate intervention efficacy, because individuals are ubiquitously exposed to the same environment, limiting the variation necessary to detect associations between contextual factors and intervention efficacy (should one exist).

Fortunately, recent advances in meta-analysis include a method for addressing this gap in the literature. Spatio-temporal meta-analyses allow for the measurement and statistical modeling of community contexts (e.g., prejudicial norms, economic inequality) and temporal dimensions (e.g., cultural trends) in relation to intervention efficacy (Johnson et al., 2017). Using this method to investigate whether particular social contexts explain heterogeneity of intervention effects may have important theoretical and practical implications. Spatio-temporal meta-analysis can be used to test conceptual models of the effects of social contexts on health, such as ecological (Bronfenbrenner, 1979) and social stress (Aneshensel \& Phelan, 1999) theories. Practically, 
spatio-temporal meta-analysis studies may shed light on where interventions have (and have not) been conducted, and can suggest the development of new, adjunctive treatment modalities to enhance intervention efficacy in contexts where they are underperforming (Johnson et al., 2017).

In one of the first applications of spatio-temporal meta-analysis to behavioral and psychological interventions, Reid and colleagues (2014) re-analyzed a previously published meta-analytic database with information on effect sizes from 78 HIV prevention interventions aimed at improving condom use among African Americans. These individual-level interventions were geographically heterogeneous - that is, they took place across the U.S. in communities that differed in levels of macro-level racism, which was operationalized via measures of anti-Black attitudes and racial residential segregation. The interventions improved condom use among African Americans only in communities with low levels of macro-level racism (i.e., those with relatively positive attitudes toward African Americans and low levels of residential segregation). Conversely, the interventions were ineffective when conducted in communities with the highest levels of racism. In addition, moderation analyses indicated that the association between macrolevel racism and intervention efficacy was strongest among adolescents, a developmental period when social identities are still developing and when external evaluations, especially of marginalized statuses, may be especially salient (e.g., Gibbons et al., 2007).

\section{The Current Study}

The current study builds on the important contributions of this previous spatio-temporal meta-analysis by: 1) examining a different feature of the social context (i.e., cultural sexism); and 2) exploring a different intervention target (i.e., psychotherapies for youth). In addition, while prior work has tended to measure macro forms of stigma and sexism at a single level of analysis (e.g., states: Homan, 2019; counties: Reid et al., 2014), the current study examined 
cultural sexism simultaneously across two geographic scales: states and counties. This dual measurement approach is important, because measuring cultural sexism at a single level of analysis (e.g., states only) may obscure heterogeneity across levels (i.e., more proximal environments may differ from state-level attitudinal contexts). Moreover, examining cultural sexism at more than one level permits the examination of cross-level interactions to determine whether cultural sexism at the state and county level interact to predict intervention efficacy. Because we examined cultural sexism at more than one level, it was necessary to measure it in similar ways across states and counties such that their association with intervention efficacy could be compared. Consistent with numerous studies that have used attitudinal indices to measure macro-level stigma (e.g., Evans-Lacko et al., 2012; Hatzenbuehler et al., 2017b; Miller et al., 2011; Leitner et al., 2016), including cultural sexism (e.g., Charles et al., 2018), we operationalized cultural sexism using a composite index of items measuring aggregated social norms. These items were obtained from two publicly available sources: (1) Project Implicit, which provided implicit gender attitudes from the Implicit Association Test (IAT) and (2) the General Social Survey, which provided explicit measures of gender role attitudes (e.g., whether it is better for women to stay home and care for children) and sexist beliefs (e.g., whether men are more emotionally suited for politics than women).

Based on theories of gender as a social structure (Risman, 2004; 2017), the work of Reid and colleagues (2014), and the emerging research on the mental health consequences of macrolevel stigma (Hatzenbuehler, 2016), we hypothesized that therapies conducted in communities with higher (vs. lower) levels of cultural sexism would be less effective in study samples with a majority of girls. We examined whether this relationship remained robust after controlling for contextual factors that may co-vary with cultural sexism and intervention efficacy, and thus serve 
as confounders. We also explored whether study characteristics known to moderate the effectiveness of youth psychotherapy interventions (Weisz et al., 2017) may bias results if they were not randomly distributed across low- and high-cultural sexism studies in our sample. Finally, to determine whether this association was specific to samples with a majority of girls, a specificity analysis examined whether cultural sexism moderated intervention efficacy among study samples with mostly boys. The inclusion of this negative control analysis (Lipsitch et al., 2010) helps to improve inferences; if the association between cultural sexism and intervention efficacy is found only among majority-girl samples, it improves the likelihood that results are not confounded by other contextual factors associated with cultural sexism.

\section{Methods}

\section{Information Sources and Study Selection}

We examined a subset of studies from a larger database used in previous meta-analyses, described in detail elsewhere (Weisz et al., 2017, 2019). The larger database included peerreviewed randomized controlled trials (RCTs) of youth psychotherapy published in English and identified in PsycINFO and PubMed between the years of 1963 and 2017. Studies were included if: (a) participants were selected and treated for depression, anxiety, conduct problems, and/or ADHD, (b) the mean sample age was between 4 and 18 years, (c) participants were randomly assigned to a treatment versus control condition and at least one treatment condition was psychotherapy, and (d) outcome measures were administered to both treatment and control groups. Studies were reliably coded for several study and sample characteristics, study quality indicators, and moderators examined in the original meta-analysis (additional data collection details available in Weisz et al., 2017, 2019).

\section{Inclusion Criteria}


In the present meta-analysis, studies were included if they (a) provided data on sample gender composition, (b) were conducted in the U.S., and (c) provided post-treatment scores on an outcome targeted by the intervention (e.g., a depression measure for a depression treatment RCT). With respect to the first inclusion criterion, nine studies occurred in multiple states. In sensitivity analyses, we removed these to ensure that their inclusion did not influence the direction or magnitude of the findings (see Online Supplement, Section S1). With respect to the third inclusion criterion, we examined clinical outcomes specifically targeted by the intervention, rather than including the diverse array of non-targeted, non-mental health measures sometimes included in study measurement models (e.g., time spent traveling to treatment sessions, marital relationship of parents), consistent with previous meta-analyses focused on clinical outcomes that the treatments were designed to impact (e.g., Weisz et al., 2019).

Consistent with clinical research trials in general (Phillips \& Hamberg, 2016), most youth psychotherapy studies do not report sex-specific outcome data (e.g., data allowing for the calculation of separate effect sizes (ESs) for girls and boys). Consequently, primary analyses were limited to studies $(N=93)$ with samples comprised of $50 \%$ or more girls (see Online Supplement, References S1). We chose this cutoff for several reasons: (1) a prior study examining associations between macro-level racism and intervention efficacy among majorityBlack samples used this same cut-off (Reid et al., 2014); (2) it ensures sufficient statistical power (i.e., a more stringent cut-off would reduce the sample size); and (3) it avoids potential selection bias if we were to examine our research question using only the very small number of studies that were conducted with $100 \%$ girls $(n=12)$. Given that gender composition of the studies is a binary variable, and that some studies included 50/50 girls/boys, using $\geq 50 \%$ boys would result 
in redundancies across models. Consequently, the negative control analysis is presented using intervention samples with greater than $50 \%$ boys.

\section{Moderator Calculation}

Consistent with prior work on macro-level prejudice related to race (e.g., Hehman et al., 2019) and sexuality (e.g., Hatzenbuehler et al., 2017) we aggregated individual implicit and explicit attitudes of sexism to the contextual level (states, counties) to create our measure of cultural sexism. State-level cultural sexism was calculated using a composite index of 11 items that were compiled via explicit and implicit attitudinal indicators ( $n=19$ candidate indicators) from 2 sources: Project Implicit (pooled across years 2003-2018) and the General Social Survey (pooled across years 1974-2014). The explicit indicators directly queried sexist attitudes (e.g., whether it is better for women to stay home and care for children). The implicit indicators were obtained through the Implicit Association Test (IAT), examining to what extent respondents associate gender with career and scientific domains. Although implicit and explicit measures of prejudice are typically only weakly correlated at the individual level, when aggregated to the contextual level (e.g., states), they are more highly correlated (e.g., Hehman et al., 2019). An examination of the two IAT measures (science and career) and the sum of the explicit sexist attitudes from Project Implicit in our data shows findings that are consistent with these patterns: state-level explicit attitudes were strongly correlated with both IAT science $(r=0.51, p<0.001)$ and IAT career $(r=0.54, p<0.001)$. Further, these variables loaded onto a single factor (described below), providing additional evidence that they represent a single construct of cultural sexism. Nevertheless, because prior research has examined implicit and explicit measures of (racial) prejudice separately (e.g., Hehman et al., 2019), we also examined these measures as independent moderators of intervention efficacy at both the state and county levels. To do so, we 
created a factor representing the individual variables measuring explicit cultural sexism. The two implicit variables were examined as individual moderators, as factor analyses with fewer than 3 indicators may be unreliable and unstable (MacCallum et al., 1999).

These items were pooled and averaged to the state level (see Online Supplement, Section S2 and Table S1 for details). A factor score was created for each state by using exploratory factor analysis with a factor loading cut off of 0.50 (see all scores in Online Supplement, Table S2). The analysis was performed using PROC FACTOR in SAS 9.4, with the prior communality estimate fixed at squared multiple correlations with all other variables and oblimin rotation. Cultural sexism was also treated categorically using the "factor" function in the R metafor package (Viechtbauer, 2010), allowing us to simultaneously compare low and high levels of cultural sexism observed in the final sample. Across the 32 states included in our analytic sample, cultural sexism ranged from -1.91 to $1.89(M=-0.30, S D=0.86$; Figure 1$)$. The majority of studies $(n=51, k=308)$ were conducted in states with lower levels of cultural sexism, with only 26 studies $(k=232)$ conducted in states with cultural sexism higher than the national average (i.e., above 0 ). To calculate county-level sexism across 75 counties in the analytic sample (see methods for identifying counties in the Online Supplement Section S2), we retained 8 of the 11 indicators from the state-level models that were also available at the county level (described in the Online Supplement, Section S2) and ran a confirmatory factor analysis with these items; counties were then assigned factor scores. As in the state-level analyses, the majority of studies in the analytic sample took place in counties with aggregate sexism levels lower than $0(n=87$, $k=632)$, with cultural sexism ranging from -1.45 to $0.27(M=-0.7, S D=0.37)$.

\section{Covariates}


We considered 6 state-level factors that could theoretically serve as common causes of both cultural sexism and intervention efficacy (i.e., effect size; ES) but that had not been used as indicators of macro-level sexism in prior work (e.g., religiosity): population density; two demographic characteristics associated with gender norms (percent foreign born, percent nonHispanic White); two indicators of area-level income (percent poverty, median household income); and an indicator of inequality (Gini coefficient). The two indicators of area-level income were significantly associated with both cultural sexism and ES, but highly correlated with each other $(r=0.68, p<.01)$, raising concerns about the potential for multi-collinearity. Thus, only median income, which was more strongly correlated with ES and cultural sexism, was included as a covariate in the main analyses. The correlation matrix, data sources, descriptions, and years are in the Online Supplement (Table S3, Section S3).

We additionally examined one study-level variable and two ES-level variables that predicted intervention efficacy in the larger meta-analytic database (Weisz et al., 2019): 1) targeted problem (e.g., internalizing problems); 2) informant (e.g., youth-reported symptoms); and 3) control condition (e.g., waitlist, usual care). While these are not confounders (i.e., they could not plausibly cause cultural sexism), if these study-level characteristics exhibit similar geographic heterogeneity to state-level cultural sexism, it could spuriously influence results. That is, if the majority of study-level characteristics were coincidentally clustered in high-sexism states, it could create an apparent association between cultural sexism and ES that was due to chance distributional differences alone. To rule out this possibility, we examined whether these characteristics were related to cultural sexism and ES and found that they were not (see Online Supplement, Section S3); thus, these variables were not controlled in our analysis.

\section{Statistical Analyses}


Cohen's $d$ was calculated for each study outcome measure (i.e., effect size; ES), reflecting the standardized mean difference between treatment and control groups at the end of treatment. ES was calculated using both sampling variation for each ES (Level 1) and withinstudy variation (Level 2). Hedges small sample correction was then added to all ESs to produce an unbiased estimate of the population standardized mean difference $(g)$ (Hedges \& Olkin, 1985). To reduce bias, all analyses weighted ES by the inverse of the sampling variance (Hedges \& Olkin, 1985), and the residual degrees of freedom was used to compute the denominator degrees of freedom for fixed effects. Weighting increases the efficiency of estimates by giving more weight to ESs with greater precision (i.e., smaller standard errors; Hedges et al., 2010). Weighted two-level random-effects models (Cheung, 2014) were conducted with the metafor package of R Version 3.5.1. Random effects models allow for a distribution of true ES, rather than assuming one true effect exists across studies (Lipsey \& Wilson, 2001; see Online Supplement, Section S5 for analysis code).

Due to the many shortcomings associated with choosing just one ES or averaging ESs (Cheung, 2014), all ESs measuring a problem targeted by the intervention were included. Because this violated the assumption of independent ESs, we ran a sensitivity analysis accounting for clustering within studies using robust variance estimation (RVE). Results from this model (presented in the Online Supplement, Section S4) were identical in direction and magnitude (i.e., the beta estimates were unchanged) but were no longer statistically significant, which likely reflects the substantial reduction in statistical power that occurs in these nested models. For dependency to introduce bias related to our research question (i.e., be a confounder), however, studies with more ESs would have to 1) be associated with our moderator- that is, studies with more ESs would have to be more likely to occur in higher cultural sexism states- 
and 2) be more likely to influence overall study ES (i.e., mean ES; the average magnitude of difference on all outcomes between the intervention vs. control groups) compared to studies with fewer ESs. We do not find evidence for either (Section S4), which further minimizes concerns that dependency serves as a source of bias in our study.

Our analysis proceeded in several steps. We first tested an interaction between state-level cultural sexism (measured continuously) and gender composition in predicting intervention efficacy to determine whether the association between cultural sexism and ES differed for samples with more girls (vs. boys). Finding that it did, we tested our primary hypothesis through stratified meta-regression analyses, where the moderating role of state-level cultural sexism on intervention efficacy was examined separately for samples with 50\% or more girls, and for samples with more than $50 \%$ boys.

We ran two additional analyses to strengthen inferences. First, we used a more stringent cut-off to examine the association between state-level cultural sexism and intervention efficacy by restricting analyses to samples with $75 \%$ or more girls. Although this analysis reduced our statistical power, it enabled us to determine whether the association between state-level cultural sexism and intervention efficacy became stronger as the proportion of girls in the study sample increased. By increasing the specificity of our sampling criterion (i.e., increasing the threshold for majority girls from $50 \%$ to $75 \%$ ), we would anticipate that the magnitude of the effect of cultural sexism should increase (i.e., reduce any bias towards the null), if the ES is indeed associated with cultural sexism and not some related contextual factor. Such a finding would strengthen our confidence in the validity of our main findings, as other contextual, state-level characteristics related to cultural sexism would be unlikely to exhibit either a higher magnitude of effects in a more specific subsample (i.e., super-majority girls). Second, while these previous 
analyses examined state-level cultural sexism as a continuous measure, we conducted an additional analysis examining this variable as a categorical moderator representing low and high levels of cultural sexism (above and below the mean) to facilitate comparisons of standardized mean differences (i.e., predicted ESs) across these levels.

Next, we examined associations between cultural sexism and intervention efficacy at the county level in samples with $50 \%$ or more girls. To examine the cross-level interaction between county- and state-level sexism, ESs were grouped into 4 categories based on whether the cultural sexism score was above or below the sample mean: 1) high county/high state, 2) low county/high state, 3) high county/low state, 4) low county/low state. Finally, we conducted sensitivity analyses to examine generality of our findings across mental health outcomes (i.e., internalizing vs. externalizing) and treatment type (i.e., behavioral vs. non-behavioral); see Online Supplement Section S3 for these results. Consistent with recommended practices for spatial meta-analyses, we also examined whether residuals in our primary model were correlated geographically (i.e., spatial autocorrelation) by calculating Moran's I (Johnson et al., 2017). The Moran's I test did not detect residual spatial autocorrelation, suggesting that model errors were randomly distributed in space (i.e., across states) and that no model adjustments were necessary.

\section{Results}

\section{Study Selection and Study Characteristics}

Of the larger database (Weisz et al., 2019), 2,698 ESs from 314 RCTs $(N=19,739)$ met inclusion criteria for the current study (Figure 2). Our primary analytic sample included studies with $50 \%$ or more girls ( $702 \mathrm{ESs} ; 93 \mathrm{RCTs}, N=5,980)$. Therapies targeted a variety of problems, including ADHD (1 study), conduct (13 studies), anxiety (46 studies), depression (32 studies), and anxiety and depression (1 study). Studies tested one or more: youth-focused behavioral 
treatments ( $n=52$; e.g., cognitive behavioral therapy), youth-focused non-behavioral treatments ( $n=22 ;$ e.g., interpersonal psychotherapy), caregiver/family-focused behavioral treatments $(n=6$; e.g., parent child interaction training), caregiver/family-focused nonbehavioral treatments $(n=4$; e.g., attachment-based family therapy), or multiple types of treatments (e.g., youth-focused behavioral and youth-focused nonbehavioral treatments; $n=9$; see Weisz et al., 2017 for additional details about therapy categories).

Previously conducted tests of publication bias (i.e., a funnel plot, Egger's weighted regression test, trim-and-fill, and an analysis of "zero-effect" studies) and study quality (i.e., via mixed models, and included measures of participant blindness to assessment, attrition, and measurement objectivity) indicated that publication bias was present but minimally impacted results, and that study quality was unrelated to ES (see Weisz et al., 2017, 2019 for details). Associations between Cultural Sexism and Intervention Efficacy

A two-level random effects meta-regression analysis indicated a significant interaction between cultural sexism and gender composition $(p<.0001)$. Stratified analyses showed that higher state-level cultural sexism was associated with significantly lower ESs for studies with $\geq 50 \%$ girls (adjusted $\beta=-0.070, \mathrm{CI}:-0.13,-0.01, p<0.05$; Table 1); in contrast, state-level cultural sexism was unrelated to ESs in studies with $>50 \%$ boys $(N=221, k=1996$; $\beta=0.003, \mathrm{CI}:-0.03$, $0.04, p=0.86$ ). This result indicates that the association between state-level cultural sexism and intervention efficacy was specific to samples with $\geq 50 \%$ girls (Figure 3 ). The robustness of these results was further supported by an additional analysis of studies with $75 \%$ or more girls $(n=26$; $k=226$ ). The beta estimate was stronger than in studies with $50 \%$ or more girls (adjusted $\beta=-$ 0.234, CI: $-0.36,-0.11, p<0.001)$, demonstrating that the association between state-level cultural sexism and intervention efficacy became more robust as the proportion of girls in the study 
sample increased. State-level cultural sexism was subsequently examined as a categorical moderator representing low and high sexism, with values dummy coded and compared, to further probe this finding. ESs were significantly lower in states in with high cultural sexism $(g=0.20)$, compared to states with low cultural sexism $(g=0.34 ; t=-2.84, p<.005$; Table 1$)$.

The beta estimate for county-level cultural sexism was stronger than the state-level analysis, but did not reach statistical significance $(\beta=-0.103, \mathrm{CI}:-0.24,0.03, p=0.14)$. However, there was a cross-level interaction between state- and county-level cultural sexism, which revealed that studies with $50 \%$ or more girls had the strongest ESs when they were conducted in counties and states with the lowest cultural sexism $(k=214$; predicted $g=0.42, p<0.001)$. This predicted ES was significantly larger than the ESs for studies in the high county/high state group ( $k=201$; predicted $g=0.24, t=-2.8, p<0.01$ ), and in the other two groups (i.e., low county/high state $k=193$ and high county/low state $k=94 ; t s=-4.1$ and -3.2 , respectively, $p \mathrm{~s}<0.01$ ).

Analyses examining whether implicit and explicit cultural sexism separately moderated psychotherapy efficacy revealed that explicit cultural sexism at the state level was significantly associated with intervention efficacy among majority-girl samples $(b=-0.07, p<0.05)$, and this association approached significance at the county level $(b=-0.11, p=0.11)$. The association between explicit sexism and intervention efficacy among majority-girl samples held when controlling for implicit sexism (state-level: $b=-0.14, p<0.01$; county-level: $b=-0.11, p=0.10$ ). IAT science was not significantly associated with psychotherapy efficacy among majority-girl samples at either the state $(b=-0.007, p=0.82)$ or county levels $(b=-0.29, p=0.12)$, but the association was in the same direction (i.e., higher implicit sexism was associated with lower efficacy). IAT career was only available at the state level and exhibited a similar association with intervention efficacy among majority-girl samples $(b=-0.007, p=0.83)$. 


\section{Discussion}

Our spatial meta-analysis indicated that psychotherapy randomized controlled trials with samples comprised of a majority of girls were significantly less effective in states with higher vs. lower levels of cultural sexism. These results were similar across type of mental health treatment outcomes (i.e., internalizing vs. externalizing) and across treatment type (i.e., behavioral vs. nonbehavioral), providing evidence for the generality of our findings. We took several steps to evaluate the robustness of these results. First, this association was observed even after controlling for a contextual-level factor associated with cultural sexism and intervention efficacy (median household income) and for study-level characteristics associated with psychotherapy efficacy in previous meta-analyses (e.g., informant, targeted problem; Weisz et al., 2017). Second, the association between state-level cultural sexism and intervention efficacy became stronger as the proportion of girls in the study sample increased. Third, there were substantive differences between studies in states with high (predicted $g=0.34$ ) and low (predicted $g=0.20$ ) cultural sexism, indicating that specification of cultural sexism (i.e., continuous or categorical) did not influence the results. Fourth, state-level cultural sexism was unrelated to intervention efficacy for samples with a majority of boys, providing evidence of result specificity.

Results indicated that the association between state-level cultural sexism and intervention efficacy among majority-girl samples was driven by the aggregate measure of explicit sexism, even when controlling for implicit sexism. In contrast, implicit sexism was not associated with intervention efficacy among majority-girl samples. Previous studies using aggregate measures of implicit and explicit racism have tended to show that both independently predict the same outcomes (Hehman et al., 2019). However, the relative strength of associations often differs when both variables are entered simultaneously, with some studies showing stronger associations 
with explicit racism (e.g., circulatory diseases; Leitner et al., 2016) and others with implicit racism (e.g., lethal force in policing; Hehman et al., 2018). One important difference among these studies is how implicit attitudes are assessed at the contextual level. Whereas most research on regional racism has measured implicit associations between race (Black/White) and valence (e.g., good/bad) categories (Hehman et al., 2019), our measures of cultural sexism capture implicit gender stereotypes (i.e., regarding science and career), which are less strongly associated with explicit sexism ( $r=0.51$ and .54 , respectively) then are explicit and implicit racism $(r=0.85$ for White participants at the state level; Hehman et al., 2019). Thus, it will be important for future research to determine whether our results are consistent across different aggregate measures of implicit sexism.

The estimate for county-level cultural sexism was comparable to the state-level estimate but did not reach statistical significance. This may be due to less precision at the county level, as fewer respondents contributed to the attitudinal measures at this geographic level, introducing measurement error in estimating the true mean values of county-level sexism. In addition, the range of county-level cultural sexism was smaller than that at the state level, restricting variability, and thus statistical power. However, the cross-level interaction between state- and county-level cultural sexism was statistically reliable, indicating that the strongest benefits of psychotherapy studies with a majority of girls were observed in states and counties with the lowest levels of cultural sexism.

Spatial meta-analysis is uniquely suited to addressing our research question, because it capitalizes on the substantial heterogeneity in exposure to cultural sexism across individual studies. Because these individual studies are typically conducted in a single location, the context is invariant, and thus it is not possible to detect associations between contextual factors and 
intervention efficacy. As such, these results provide a novel demonstration that cultural sexism may undermine the efficacy of psychotherapy interventions for samples with a majority of girls.

At the same time, our approach is less well-suited for answering questions of mechanism - that is, why therapies in high cultural sexism states are less effective among study samples with more girls. Given established associations between community-level prejudice and adverse psychosocial outcomes (Hatzenbuehler, 2016; 2017), it is possible that girls in communities with high levels of cultural sexism arrive at treatment with elevated mental health symptoms and other psychosocial problems that render them less able to derive benefit from psychotherapy. Alternatively, girls may enter treatment in high and low sexism communities with similar levels of psychopathology, but cultural sexism may increase risk for certain psychosocial processes that negatively affect treatment engagement and/or retention once therapy is initiated. In preliminary support of this idea, macro-level stigma is associated with higher levels of social isolation (Perales \& Todd, 2018), hypervigilance and hopelessness (Russell \& Richards, 2003), and perceived stress (Rostosky et al., 2009), some of which impede upon intervention uptake or response, or both (Alfano et al., 2009; Gallagher \& Resick, 2012). Finally, it is possible that cultural sexism continually undermines any gains made in psychotherapy because these contexts lack the type of structural supports necessary for girls to incorporate the skills learned in therapy into their daily lives. We are unable to test these competing explanations because, like all meta-analyses, we are limited by the data that could be reliably coded across studies. Future research is therefore needed to identify the causal mechanisms underlying our findings, which can point to the most effective ways to modify psychotherapies delivered in environments characterized by high levels of cultural sexism to ensure that they are maximally efficacious. 
While the concept of macro-level sexism — in both its material and cultural dimensionshas existed for decades (e.g., Epstein, 1988), most research examines material forms of macrolevel sexism (e.g., Homan, 2019). We advance this literature by measuring cultural dimensions of macro-level sexism using state- and county-level attitudinal measures. However, given that this field is still in its infancy, there is not yet a consensus on the best way to measure this construct. We offer an empirically-derived approach to quantifying cultural sexism, but further research is needed to determine the relative validity and precision of competing measurement approaches. For example, better understanding psychometric properties such as convergent (i.e., associations with other, theoretically-consistent outcomes) and discriminant (i.e., lack of association with other, theoretically-inconsistent outcomes) validity, and test-retest reliability, will be essential to advancing this field.

Studies of other aggregate regional measures of explicit bias (e.g., racism) have shown that such exposures can be validly and reliably measured (e.g., Hehman et al., 2019). However, research has not yet addressed issues of measurement invariance - that is, whether contextual indicators of racism or sexism measure the same construct across different states and counties. Evaluating this question poses conceptual and methodological challenges. Unlike individuallevel measures, where invariance is typically examined across demographic characteristics (e.g., sex, age), assessing invariance across contextual characteristics (e.g., area-level conservatism) is difficult because these factors are either highly correlated with sexism, raising concerns of multicollinearity, or may influence sexism, raising concerns of construct validity. Further, willingness to endorse explicit sexism - which is a potential source of invariance in individuallevel measures - may vary across states and counties. Yet, capturing such variation in contextual-level exposures is an important component of measuring social climate, because a 
greater willingness to endorse the expression of sexism should result in social contexts that heighten social identity threat (Major \& O’Brien, 2005) for women and girls. If that is the case, sources of measurement invariance may differ across individual and contextual measures. Future methodological research is therefore needed to evaluate measurement invariance for cultural sexism and other aggregate measures of prejudice.

Our results are consistent with those of Reid and colleagues (2014), who found that a health behavior intervention for African Americans was less effective in areas high in racial prejudice. Thus, there is now evidence across two studies focusing on different forms of macrolevel stigma and prejudice (racism, sexism) and different intervention foci (HIV prevention interventions, psychotherapy) showing that psychological interventions conducted in communities with higher levels of stigma are less effective than those conducted in low-stigma contexts. It is therefore worth considering the implications of these emerging results for clinical and public health interventions. If future research continues to replicate this finding, there would be additional evidence that cultural sexism should be addressed via structural- and communitylevel interventions to enhance the success of psychotherapies conducted and disseminated in these contexts. While structural interventions to reduce sexism are rare, examples of structural approaches in other areas (e.g., Chaudoir et al., 2017) support the utility of this approach.

At the same time, changing social structures can be a protracted process, and thus clinical interventions are necessary to assist individuals in high-sexism contexts to cope effectively. In their meta-analytic study, Reid et al. (2014) found that interventions that tailored content to participants' values and needs buffered against the adverse impact of macro-level racism on African Americans' condom use, perhaps by reducing respondents' distrust of intervention providers. The extent to which analogous forms of tailoring may improve girls' therapy response 
in the context of cultural sexism remains an open question. However, there is growing support for the utility of the core components of feminist psychotherapy (Conlin, 2017), including an egalitarian and empowering client-therapist relationship (Arczynski \& Morrow, 2017; Tryon \& Winograd, 2011) and attending to oppression in treatment (Owen et al., 2014; Pachankis, 2015). Drawing on gender-affirming models of therapy - often employed with, though not exclusive to, transgender clients - growing research suggests that psychotherapy outcomes might be improved by attending to gender-based systems of power and privilege in treatment (e.g., addressing gender dynamics explicitly, incorporating advocacy and activism; Budge \& Moradi, 2018). Further, recent research (Pachankis et al., 2020) has demonstrated that brief, online interventions that promote personal (e.g., self-acceptance) and interpersonal (e.g., social support) coping are effective in reducing psychological distress among sexual minority youth living in high-stigma, low-resource settings (i.e., Appalachia). This dual focus on individual and structural levels aligns with best practices in intervention research, as it is increasingly recognized that multi-level approaches are needed to reduce stigma and its negative consequences (e.g., Rao et al., 2019).

Our study has several limitations. First, our sample was limited to the United States and included only 32 states and 75 counties, which resulted in a restricted range of cultural sexism. Of note, no studies with majority-girl samples in the larger meta-analytic database were conducted in states and counties with the highest levels of cultural sexism and thus our sample over-represented treatment trials in places with lower levels of cultural sexism. However, this restricted range would have reduced our statistical power; thus, we have likely underestimated the association between cultural sexism and psychotherapy efficacy among samples with a majority of girls. In addition, this finding is important in its own right, because it suggests that empirical tests of psychotherapy interventions may not be as common in higher-sexism contexts 
as in lower-sexism contexts. Future meta-analyses should examine psychotherapy efficacy outside the United States to determine whether our results generalize to different cultural contexts.

Second, our study focuses on interventions for the most commonly targeted problems in youth psychotherapy (Weisz, 2004): depression, anxiety, conduct, and ADHD. Future research should examine mental health problems that are overrepresented in girls (relative to boys), such as eating disorders (Allen et al., 2013), posttraumatic stress disorder (PTSD; Alisic et al., 2014), and complex PTSD (Herman, 1997), or difficulties that manifest differently across girls and boys, such as borderline personality disorder symptomatology (Bradley et al., 2005).

Third, the datasets that we used to create the cultural sexism index had small sample sizes of survey respondents in most states and counties within individual years. Consequently, cultural sexism was aggregated across years to create a more stable estimate, and then analyzed as a time-invariant predictor. One potential limitation of this approach is that it does not capture changes in temporal trends in sexism. However, previous analyses of attitudinal data from the 1977-1998 General Social Survey, from which we obtained our explicit measures of cultural sexism, showed that while sexism decreased over time, the ranking of each state's measure of cultural sexism relative to other states was stable across time (Charles et al., 2018). In other words, places with higher cultural sexism in previous decades tend to remain so today despite national declines in sexism overall, suggesting that a time-invariant measure represents a valid way to capture cultural sexism. Further, any misclassification in our pooled measure would be unlikely to be systematically related to the outcome (i.e., it would introduce random measurement error), which would bias results towards the null. Nevertheless, future research 
should determine whether our results are consistent when modeling cultural sexism as a timevarying moderator of intervention efficacy.

Fourth, residual confounding is a concern for observational studies, particularly when examining associations between contextual exposures and individual health outcomes. We are, of course, unable to randomize residents into varying cultural sexism exposures, and thus rely on two design choices to minimize the likelihood that the findings are not due to third variable bias. The first is confounder control; our findings were robust to inclusion of other structural covariates which may have confounded the relationship. The second is the negative control test among boys, which suggested that the effects of the cultural sexism were specific to girls. Residual confounding by a third, unmeasured variable would likely not show such specificity, but would rather influence both groups in similar ways. In other words, if cultural sexism is merely a proxy for other contextual factors (e.g., socioeconomic status, conservatism), it should operate similarly (i.e., be associated with reduced treatment efficacy) among both boys and girls.

We are also reassured by the consistency of our findings with regard to other studies examining contextual, material sexism (e.g., gender differences in the wage gap or employment), which have found similar associations across a variety of health outcomes, including mental health (King, 2020; Chen et al., 2005). Moving forward, studies of cultural sexism would benefit from the triangulation of evidence from a variety of design approaches in order to further minimize the threats posed by residual confounding, such as quasi-experimental studies, which have been used to explore structural/contextual forms of stigma for other groups (Hatzenbuehler, 2016). Thus, while the results from the current study, together with other research (e.g., Chen et al., 2005; King, 2020), provide preliminary support for the utility of addressing cultural sexism 
to improve intervention efficacy, caution is warranted until the evidentiary base for the mental health consequences of cultural sexism is further strengthened.

Finally, consistent with best practices in meta-analysis (Cheung, 2014), we included multiple outcomes (i.e., ESs), yet did not account for ES-dependency because of the significant loss of power when ES-dependency was adjusted for (see Online Supplement, Section S4). Although this did not influence the direction or magnitude of our findings, future research with larger sample sizes is nevertheless warranted to corroborate our results.

This is the first study to document that the social context surrounding girls may partially explain heterogeneity of treatment effects in therapies. Our findings suggest new avenues of research investigating whether existing psychotherapies might be adapted to enhance their effects among girls in environments with pronounced cultural sexism, and possibly a need for structural- and community-level interventions to target cultural sexism at its source. This research also joins an emerging body of evidence suggesting that the efficacy of psychological interventions may depend in part on the social contexts in which they are delivered (Johnson et al., 2017; Reid et al., 2014). 


\section{References}

Albizu-Garcia C, Alegría M, Freeman D, Vera M: Gender and health services use for a mental health problem. Soc Sci Med. 2001, 53 (7): 865-878. 10.1016/S0277-9536(00)00380-4.

Alfano, C. A., Pina, A. A., Villalta, I. K., Beidel, D. C., Ammerman, R. T., \& Crosby, L. E. (2009). Mediators and moderators of outcome in the behavioral treatment of childhood social phobia. Journal of the American Academy of Child \& Adolescent Psychiatry, 48(9), 945-953. https://doi.org/10.1097/CHI.0b013e3181af8216

Alisic, E., Zalta, A. K., Wesel, F. van, Larsen, S. E., Hafstad, G. S., Hassanpour, K., \& Smid, G. E. (2014). Rates of post-traumatic stress disorder in trauma-exposed children and adolescents: Meta-analysis. The British Journal of Psychiatry, 204(5), 335-340.

Aneshensel, C., \& Phelan, J. C. (1999). Handbook of the sociology of mental health. Kluwer Academic / Plenum Publishers.

Arczynski, A. V., \& Morrow, S. L. (2017). The complexities of power in feminist multicultural psychotherapy supervision. Journal of Counseling Psychology, 64(2), 192-205. http://dx.doi.org/10.1037/cou0000179

Bronfenbrenner, U. (1979). The ecology of human development. the President and Fellows of Harvard College.

Brown, L. S. (2006). Still subversive after all these years: The relevance of feminist therapy in the age of evidence-based practice. Psychology of Women Quarterly, 30(1), 15-24.

Brown, L. S. (2018). Feminist therapy, 2nd ed (pp. xvi, 188). American Psychological Association. https://doi.org/10.1037/0000092-000

Bryant-Davis, T. (2019). Multicultural feminist therapy: Helping adolescent girls of Color to thrive. American Psychological Association. 
Budge, S. L., \& Moradi, B. (2018). Attending to gender in psychotherapy: Understanding and incorporating systems of power. Journal of Clinical Psychology, 74(11), 2014-2027. https://doi.org/10.1002/jclp.22686

Chandra, A., \& Minkovitz, C. S. (2006). Stigma starts early: Gender differences in teen willingness to use mental health services. Journal of Adolescent Health, 38(6), 754-e1.

Charles, K. K., Guryan, J., \& Pan, J. (2018). The effects of sexism on American women: The role of norms vs. discrimination (Working Paper No. 24904). National Bureau of Economic Research. https://doi.org/10.3386/w24904

Chaudoir, S. R., Wang, K., \& Pachankis, J. E. (2017). What reduces sexual minority stress? A review of the intervention “toolkit.” The Journal of Social Issues, 73(3), 586-617. https://doi.org/10.1111/josi.12233

Chen, Y.-Y., Subramanian, S. V., Acevedo-Garcia, D., \& Kawachi, I. (2005). Women's status and depressive symptoms: A multilevel analysis. Social Science \& Medicine, 60(1), 4960. https://doi.org/10.1016/j.socscimed.2004.04.030

Cheung, M. W.-L. (2014). Modeling dependent effect sizes with three-level meta-analyses: A structural equation modeling approach. Psychological Methods, 19(2), 211-229. https://doi.org/10.1037/a0032968

Conlin, S. E. (2017). Feminist therapy: A brief integrative review of theory, empirical support, and call for new directions. Women's Studies International Forum, 62, 78-82.

Corrigan, P. W., Markowitz, F. E., \& Watson, A. C. (2004). Structural levels of mental illness stigma and discrimination. Schizophrenia Bulletin, 30(3), 481-491.

Epstein, C. F. (1988). Deceptive distinctions: Sex, gender, and the social order. Russell Sage Foundation. 
Evans-Lacko, S., Brohan, E., Mojtabai, R., \& Thornicroft, G. (2012). Association between public views of mental illness and self-stigma among individuals with mental illness in 14 European countries. Psychological Medicine, 42(8), 1741-1752. https://doi.org/10.1017/S0033291711002558

Flores, E., Fuhr, D., Bayer, A., Lescano, A., Thorogood, N., \& Simms, V. (2017). Mental health impact of social capital interventions: A systematic review. Social Psychiatry and Psychiatric Epidemiology, 53, 107-119. https://doi.org/10.1007/s00127-017-1469-7

Fowler, P., Tompsett, C., Braciszewski, J., Jacques-Tiura, A., \& Baltes, B. (2009). Community violence: A meta-analysis on the effect of exposure and mental health outcomes of children and adolescents. Development and Psychopathology, 21(1), 227-259. https://doi.org/10.1017/S0954579409000145

Frost, D. M. (2020). Hostile and harmful: Structural stigma and minority stress explain increased anxiety among migrants living in the United Kingdom after the Brexit referendum. Journal of Consulting and Clinical Psychology, 88(1), 75-81. https://doi.org/10.1037/ccp0000458

Gagné, S., Vasiliadis, H.-M., \& Préville, M. (2014). Gender differences in general and specialty outpatient mental health service use for depression. BMC Psychiatry, 14(1), 135.

Gallagher, M. W., \& Resick, P. A. (2012). Mechanisms of change in cognitive processing therapy and prolonged exposure therapy for PTSD: Preliminary evidence for the differential effects of hopelessness and habituation. Cognitive Therapy and Research, 36(6), 750-755. https://doi.org/10.1007/s10608-011-9423-6

Gaub, M., \& Carlson, C. L. (1997). Gender Differences in ADHD: A Meta-Analysis and Critical Review. Journal of the American Academy of Child, 36(8), 1036-1046. 
Gibbons, F. X., Yeh, H.-C., Gerrard, M., Cleveland, M. J., Cutrona, C., Simons, R. L., \& Brody, G. H. (2007). Early experience with racial discrimination and conduct disorder as predictors of subsequent drug use: A critical period hypothesis. Drug and Alcohol Dependence, 88, S27-S37. https://doi.org/10.1016/j.drugalcdep.2006.12.015

Gillespie, L. K., \& Reckdenwald, A. (2017). Gender equality, place, and female-victim intimate partner homicide: A county-level analysis in North Carolina. Feminist Criminology, 12(2), 171-191. https://doi.org/10.1177/1557085115620479

Gorey, K. M., Daly, C., Richter, N. L., Gleason, D. R., \& McCallum, M. J. A. (2003). The effectiveness of feminist social work methods: An integrative review. Journal of Social Service Research, 29(1), 37-55. https://doi.org/10.1300/J079v29n01_02

Hatzenbuehler, M. L. (2017). Structural stigma and health. In B. Major, J.F. Dovidio, \& B.G. Link, (Eds.), The Handbook of Stigma, Discrimination and Health (pp. 105-121). Oxford: Oxford University Press.

Hatzenbuehler, M. L. (2016). Structural stigma and health inequalities: Research evidence and implications for psychological science. The American Psychologist, 71(8), 742-751. https://doi.org/10.1037/amp0000068

Hatzenbuehler, M. L., Flores, A. R., \& Gates, G. J. (2017). Social Attitudes Regarding Same-Sex Marriage and LGBT Health Disparities: Results from a National Probability Sample. Journal of Social Issues, 73(3), 508-528. https://doi.org/10.1111/josi.12229

Hatzenbuehler, M. L., \& Link, B. G. (2014). Introduction to the special issue on structural stigma and health. Social Science \& Medicine (1982), 103, 1-6. https://doi.org/10.1016/j.socscimed.2013.12.017 
Hatzenbuehler, M. L., \& McLaughlin, K. A. (2017). Sex, sexual orientation, and depression. https://doi.org/10.1093/oxfordhb/9780199973965.013.5

Hatzenbuehler, M. L., \& Pachankis, J. E. (2016). Stigma and Minority Stress as Social Determinants of Health Among Lesbian, Gay, Bisexual, and Transgender Youth. Pediatric Clinics of North America, 63(6), 985-997. https://doi.org/10.1016/j.pcl.2016.07.003

Hatzenbuehler, M. L., Phelan, J. C., \& Link, B. G. (2013). Stigma as a Fundamental Cause of Population Health Inequalities. American Journal of Public Health, 103(5), 813-821. https://doi.org/10.2105/AJPH.2012.301069

Hedges, L. V. (2006). 29 Meta-Analysis. In Handbook of Statistics (Vol. 26, pp. 919-953). Elsevier. https://doi.org/10.1016/S0169-7161(06)26029-2

Hedges, L. V., \& Olkin, I. (1985). Statistical Methods for Meta-analysis. Academic Press. Hedges, L. V., Tipton, E., \& Johnson, M. C. (2010). Robust variance estimation in metaregression with dependent effect size estimates. Research Synthesis Methods, 1(1), 3965. https://doi.org/10.1002/jrsm.5

Hehman, E., Calanchini, J., Flake, J.K., \& Leitner, J.B. (2019). Establishing construct validity evidence for regional measures of explicit and implicit racial bias. Journal of Experimental Psychology: General, 48(6), 1022-1040.

Hehman, E., Flake, J. K., \& Calanchini, J. (2018). Disproportionate use of lethal force in policing is associated with regional racial biases of residents. Social Psychological \& Personality Science, 9, 393-401.

Homan, P. (2019). Structural Sexism and Health in the United States: A New Perspective on Health Inequality and the Gender System. https://doi.org/10.1177/0003122419848723 
Hunnicutt, G. (2007). Female status and infant and child homicide victimization in rural and urban counties in the U.S. Gender Issues, 24(3), 35-50. https://doi.org/10.1007/s12147007-9046-0

Israeli, A. L., \& Santor, D. A. (2000). Reviewing effective components of feminist therapy. Counselling Psychology Quarterly, 13(3), 233-247. https://doi.org/10.1080/095150700300091820

Johnson, B. T., Cromley, E. K., \& Marrouch, N. (2017). Spatiotemporal meta-analysis: Reviewing health psychology phenomena over space and time. Health Psychology Review, 11(3), 280-291. https://doi.org/10.1080/17437199.2017.1343679

Kessler, R. C., Chiu, W. T., Demler, O., \& Walters, E. E. (2005). Prevalence, Severity, and Comorbidity of Twelve-month DSM-IV Disorders in the National Comorbidity Survey Replication (NCS-R). Archives of General Psychiatry, 62(6), 617627.https://doi.org/10.1001/archpsyc.62.6.617

King, T. L., Kavanagh, A., Scovelle, A. J., \& Milner, A. (2020). Associations between gender equality and health: A systematic review. Health Promotion International, 35(1), 27-41. https://doi.org/10.1093/heapro/day093

Koenen, K. C., Lincoln, A., \& Appleton, A. (2006). Women's status and child well-being: A state-level analysis. Social Science \& Medicine, 63(12), 2999-3012. https://doi.org/10.1016/j.socscimed.2006.07.013

Leitner, J. B., Hehman, E., Ayduk, O., \& Mendoza-Denton, R. (2016). Blacks' death rate due to circulatory diseases is positively related to Whites' explicit racial bias: a nationwide investigation using Project Implicit. Psychological Science, 27(10), 1299-1311. https://doi.org/10.1177/0956797616658450 
Link, B. G., \& Phelan, J. C. (2001). Conceptualizing stigma. Annual Review of Sociology, 27(1), 363-385. https://doi.org/10.1146/annurev.soc.27.1.363

Lipsey, M., \& Wilson, D. (2001). Practical meta-analysis. https://idostatistics.com/lipseywilson-2001-practical-meta-analysis-2001/

Lipsitch, M., Tchetgen, E. T., \& Cohen, T. (2010). Negative controls: A tool for detecting confounding and bias in observational studies. Epidemiology (Cambridge, Mass.), 21(3), 383-388. https://doi.org/10.1097/EDE.0b013e3181d61eeb

MacCallum, R. C., Widaman, K. F., Zhang, S., \& Hong, S. (1999). Sample size in factor analysis. Psychological Methods, 4(1), 84.

Major, B., \& O’Brien, L. (2005). The social psychology of stigma. Annual Review of Psychology, 56, 393-421. https://doi.org/10.1146/annurev.psych.56.091103.070137

McLaughlin, K. A., Xuan, Z., Subramanian, S. V., \& Koenen, K. C. (2011). State-level women’s status and psychiatric disorders among US women. Social Psychiatry and Psychiatric Epidemiology, 46(11), 1161-1171. https://doi.org/10.1007/s00127-010-0286-z

Mennies, R. J., Birk, S. L., Norris, L. A., \& Olino, T. M. (2021). The main and interactive associations between demographic factors and psychopathology and treatment utilization in youth: A test of intersectionality in the ABCD Study. Research on Child and Adolescent Psychopathology, 49(1), 5-17. https://doi.org/10.1007/s10802-020-00687-8

Merikangas, K. R., He, J., Burstein, M., Swendsen, J., Avenevoli, S., Case, B., Georgiades, K., Heaton, L., Swanson, S., \& Olfson, M. (2011). service utilization for lifetime mental disorders in u.s. adolescents: Results of the National Comorbidity Survey-Adolescent Supplement (NCS-A). Journal of the American Academy of Child \& Adolescent Psychiatry, 50(1), 32-45. https://doi.org/10.1016/j.jaac.2010.10.006 
Miller, C. T., Grover, K. W., Bunn, J. Y., \& Solomon, S. E. (2011). Community norms about suppression of aids-related prejudice and perceptions of stigma by people with HIV or AIDS. Psychological Science, 22(5), 579-583.

Miller, C. T., Varni, S. E., Solomon, S. E., DeSarno, M. J., \& Bunn, J. Y. (2016). Macro-level implicit HIV prejudice and the health of community residents with HIV. Health Psychology, 35(8), 807-815. https://doi.org/10.1037/hea0000314

Miller, J. B. (1976). Toward a new psychology of women. Beacon Press.

Moffitt, T. E. (2003). Life-course-persistent and adolescence-limited antisocial behavior: A 10year research review and a research agenda. In Causes of conduct disorder and juvenile delinquency (pp. 49-75). The Guilford Press.

Morey, Y., Mellon, D., Dailami, N., Verne, J., \& Tapp, A. (2017). Adolescent self-harm in the community: An update on prevalence using a self-report survey of adolescents aged 1318 in England. Journal of Public Health (Oxford, England), 39(1), 58-64.

Nilsen, T. S., Eisemann, M., \& Kvernmo, S. (2013). Predictors and moderators of outcome in child and adolescent anxiety and depression: A systematic review of psychological treatment studies. European Child \& Adolescent Psychiatry, 22(2), 69-87.

Oakley, M. A., Addison, S. C., Piran, N., Johnston, G. J., Damianakis, M., Curry, J., Dunbar, C., \& Weigeldt, A. (2013). Outcome study of brief relational-cultural therapy in a women's mental health center. Psychotherapy Research, 23(2), 137-151.

Owen, J., Tao, K. W., Imel, Z. E., Wampold, B. E., \& Rodolfa, E. (2014). Addressing racial and ethnic microaggressions in therapy. Professional Psychology: Research and Practice, 45(4), 283-290. https://doi.org/10.1037/a0037420 
Pachankis, J. E. (2015). A transdiagnostic minority stress treatment approach for gay and bisexual men's syndemic health conditions. Archives of Sexual Behavior, 44(7), 18431860. https://doi.org/10.1007/s10508-015-0480-x

Pachankis, J. E., Williams, S. L., Behari, K., Job, S., McConocha, E. M., \& Chaudoir, S. R. (2020). Brief online interventions for LGBTQ young adult mental and behavioral health: A randomized controlled trial in a high-stigma, low-resource context. Journal of Consulting and Clinical Psychology, 88(5), 429-444. https://doi.org/10.1037/ccp0000497

Payne, B. K., Vuletich, H. A., \& Lundberg, K. B. (2017). The bias of crowds: How implicit bias bridges personal and systemic prejudice. Psychological Inquiry, 28, 1-64.

Perales, F., \& Todd, A. (2018). Structural stigma and the health and wellbeing of Australian LGB populations: Exploiting geographic variation in the results of the 2017 same-sex marriage plebiscite. Social Science \& Medicine (1982), 208, 190-199.

Phillips, S. P., \& Hamberg, K. (2016). Doubly blind: A systematic review of gender in randomised controlled trials. Global Health Action, 9.

Pickett, K. E., James, O. W., \& Wilkinson, R. G. (2006). Income inequality and the prevalence of mental illness: A preliminary international analysis. Journal of Epidemiology and Community Health, 60(7), 646. https://doi.org/10.1136/jech.2006.046631

Rao, D., Elshafei, A., Nguyen, M., Hatzenbuehler, M. L., Frey, S., \& Go, V. F. (2019). A systematic review of multi-level stigma interventions: State of the science and future directions. BMC Medicine, 17(1), 41. https://doi.org/10.1186/s12916-018-1244-y

Reardon, S., \& Stuart, E. (2017). Editors' introduction: Theme issue on variation in treatment effects. Journal of Research on Educational Effectiveness, 10(4), 671-674. 
Reid, A. E., Dovidio, J. F., Ballester, E., \& Johnson, B. T. (2014). HIV prevention interventions to reduce sexual risk for African Americans: The influence of community-level stigma and psychological processes. Social Science \& Medicine, 103, 118-125.

Rhodes A, Jaakkimainen R, Bondy S, Fung K: Depression and mental health visits to physicians-a prospective records-based study. Soc Sci Med. 2006, 62 (4): 828-834.

Risman, B. J. (2004). Gender as a social structure: Theory wrestling with activism. Gender \& Society, 18(4), 429-450. https://doi.org/10.1177/0891243204265349

Risman, B. J. (2017). 2016 Southern Sociological Society presidential address: Are millennials cracking the gender structure? Social Currents, 4(3), 208-227.

Rostosky, S. S., Riggle, E. D. B., Horne, S. G., \& Miller, A. D. (2009). Marriage amendments and psychological distress in lesbian, gay, and bisexual (LGB) adults. Journal of Counseling Psychology, 56(1), 56-66. https://doi.org/10.1037/a0013609

Russell, G., \& Richards, J. (2003). Stressor and resilience factors for lesbians, gay men, and bisexuals confronting antigay politics. American Journal of Community Psychology, 31, 313-328. https://doi.org/10.1023/A:1023919022811

Salk, R. H., Hyde, J. S., \& Abramson, L. Y. (2017). Gender differences in depression in representative national samples: Meta-analyses of diagnoses and symptoms. Psychological Bulletin, 143(8), 783-822. https://doi.org/10.1037/bul0000102

Seidler, Z. E., Dawes, A. J., Rice, S. M., Oliffe, J. L., \& Dhillon, H. M. (2016). The role of masculinity in men's help-seeking for depression: A systematic review. Clinical Psychology Review, 49, 106-118.

Sen, B. (2004). Adolescent propensity for depressed mood and help seeking: race and gender differences. Journal of Mental Health Policy and Economics, 7(3), 133-145. 
Simon, A. E., Pastor, P. N., Reuben, C. A., Huang, L. N., \& Goldstrom, I. D. (2015). Use of mental health services by children ages six to 11 with emotional or behavioral difficulties. Psychiatric Services, 66(9), 930-937.

Simpson, G. A., Cohen, R. A., Pastor, P. N., \& Reuben, C. A. (2008). Use of mental health services in the past 12 months by children aged 4-17 years: United States, 2005-2006: (565112009-001) [Data set]. American Psychological Association.

Twenge, J. M., \& Nolen-Hoeksema, S. (2002). Age, gender, race, socioeconomic status, and birth cohort difference on the children's depression inventory: A meta-analysis. Journal of Abnormal Psychology, 111(4), 578-588. https://doi.org/10.1037/0021-843X.111.4.578

Tryon, G. S., \& Winograd, G. (2011). Goal consensus and collaboration. Psychotherapy, 48(1), 50-57. https://doi.org/10.1037/a0022061

Viechtbauer, W. (2010). Conducting meta-analyses in $R$ with the metafor Package. Journal of Statistical Software, 36(3). https://doi.org/10.18637/jss.v036.i03

Vieraitis, L. M., Britto, S., \& Kovandzic, T. V. (2016). The impact of women's status and gender inequality on female homicide victimization rates: Evidence from U.S. counties. Feminist Criminology. https://doi.org/10.1177/1557085106294187

Watson, H. J., \& Nathan, P. R. (2008). Role of gender in depressive disorder outcome for individual and group cognitive-behavioral treatment. Journal of Clinical Psychology, 64(12), 1323-1337. https://doi.org/10.1002/jclp.20524

Weisz, J. R., Kuppens, S., Ng, M. Y., Eckshtain, D., Ugueto, A. M., Vaughn-Coaxum, R., Jensen-Doss, A., Hawley, K. M., Krumholz Marchette, L. S., Chu, B. C., Weersing, V. R., \& Fordwood, S. R. (2017). What five decades of research tells us about the effects of 
youth psychological therapy: A multilevel meta-analysis and implications for science and practice. American Psychologist, 72(2), 79-117. https://doi.org/10.1037/a0040360

Weisz, J. R., Kuppens, S., Ng, M. Y., Vaughn-Coaxum, R. A., Ugueto, A. M., Eckshtain, D., \& Corteselli, K. A. (2019). Are psychotherapies for young people growing stronger? tracking trends over time for youth anxiety, depression, attention-deficit/hyperactivity disorder, and conduct problems. Perspectives on Psychological Science, 14(2), 216-237. 
Figure 1. Observed State-Level Cultural Sexism in Sample of Studies with Majority Girls (N=93)

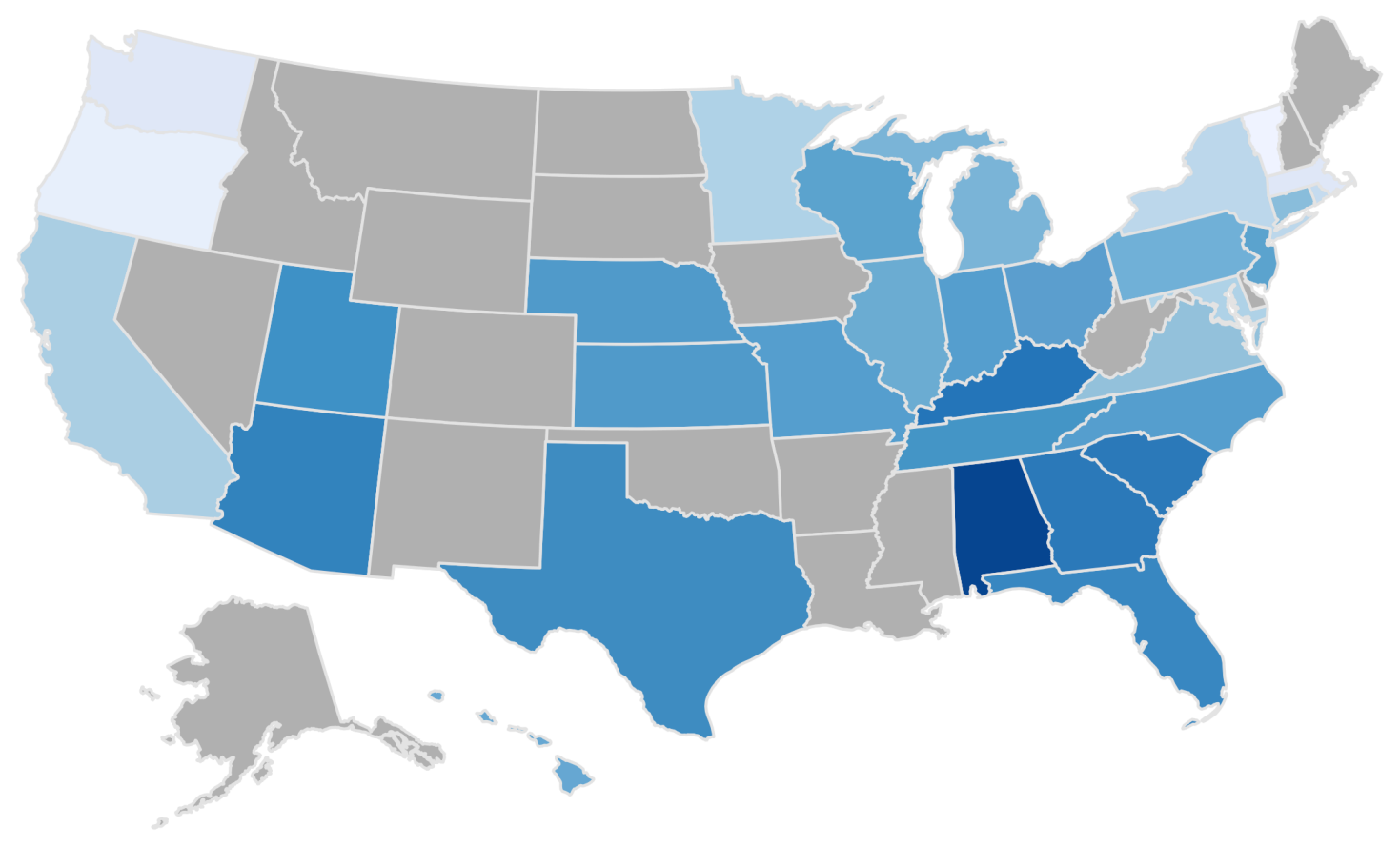

Cultural sexism (continuous)

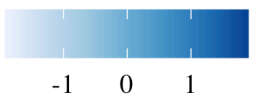

Not included 
Figure 2.

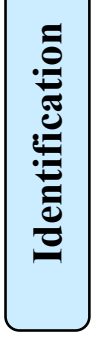

Flowchart Showing Study Retrieval, Review, Exclusion, and Inclusion in Current Meta-Analysis

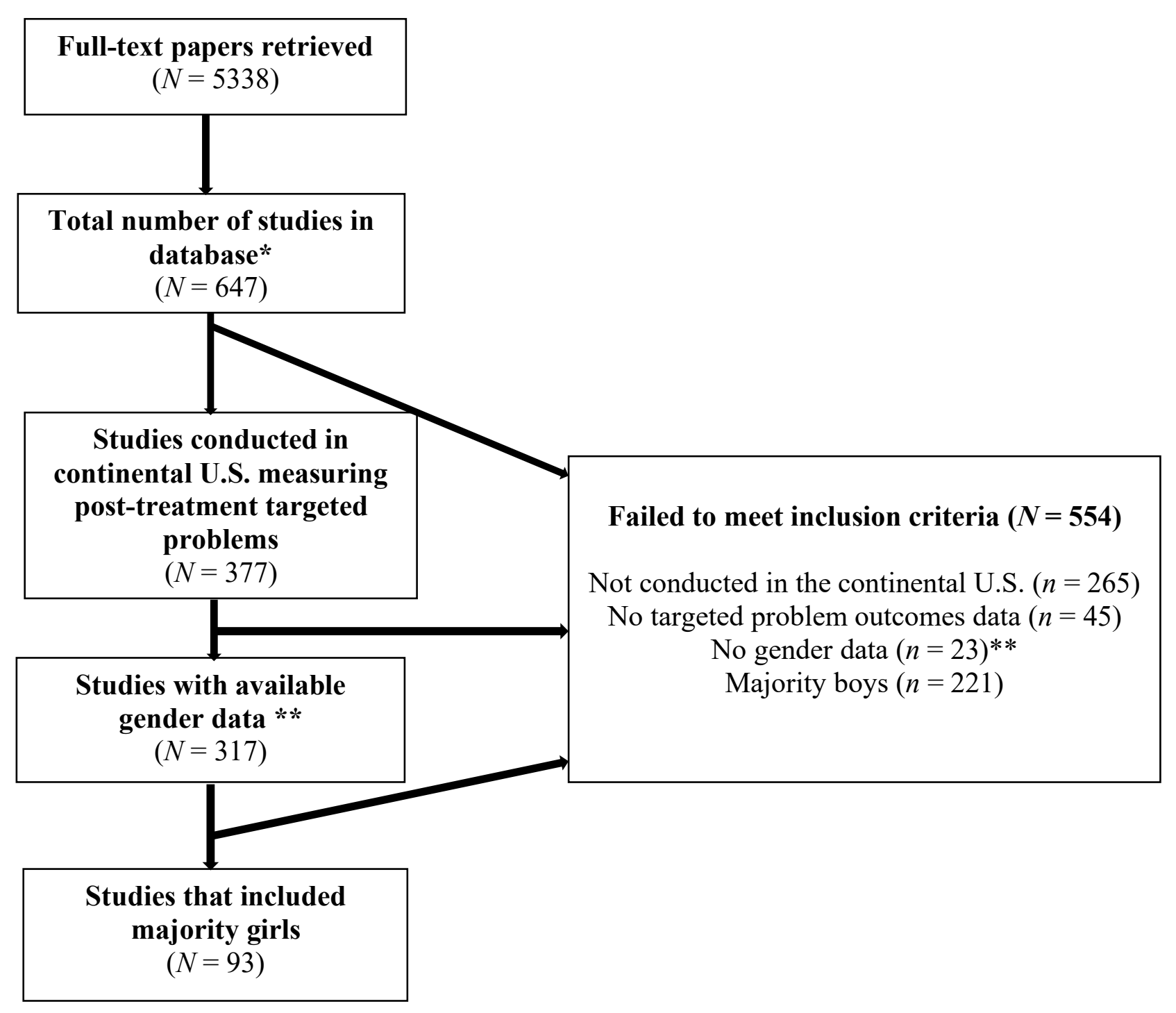

**cf. Weisz et al (2017) for more details about the larger database

** Gender data originally missing for 31 studies, most of which were published in the 1970s. After contacting multiple authors of each study (when available), 23 remained missing. Several authors could not be contacted because they were deceased, and among those who were contacted, several indicated that they did not collect gender data or could not find original study data.

***7 studies with samples of majority girls did not include state data. Accordingly, the first author of each study was contacted via email and all authors provided the state in which the study was conducted. 
Figure 3. State-level Cultural Sexism and Effect Size Across Subsets by Majority Sex

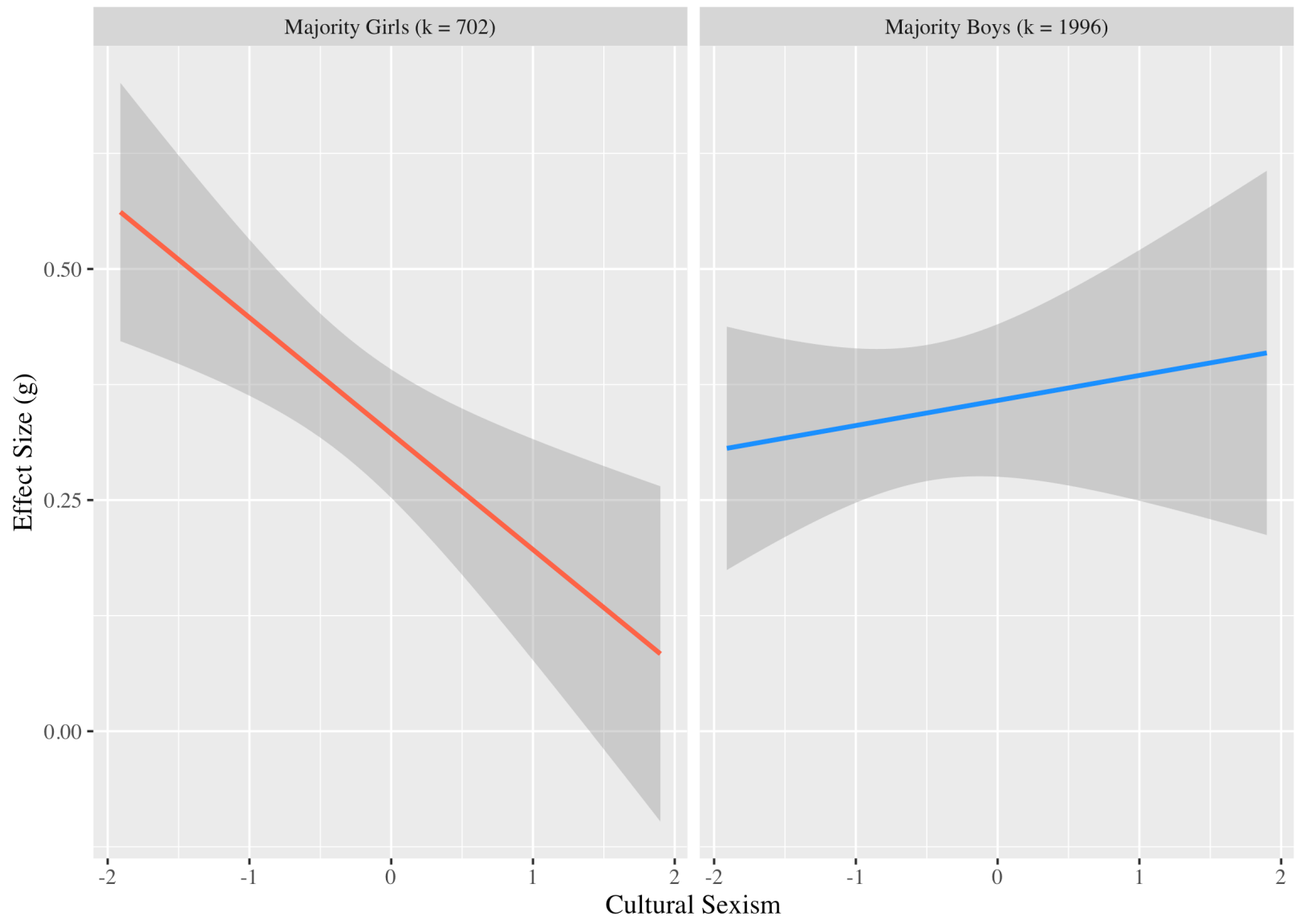




\section{Table 1}

Psychotherapy effect sizes as a function of state-level cultural sexism

\begin{tabular}{lcccc}
\hline \multicolumn{1}{c}{ Variable } & $\beta$ & $S E$ & $95 \%$ CI & $\begin{array}{l}\text { Moderator } t \text { - } \\
\text { test }(t \text {-value })\end{array}$ \\
& & & $-2.59^{*}$ \\
\hline $\begin{array}{l}\text { Unadjusted model: } \text { State-level cultural sexism without } \\
\text { covariate }\end{array}$ & -.07 & .03 & {$[-.13,-.02]$} & \\
$\begin{array}{l}\text { Adjusted model: } \text { State-level cultural sexism } \\
\text { controlling for contextual covariate } \\
\quad \text { Median household income }\end{array}$ & -.07 & .03 & {$[-.13,-.01]$} & $-2.38^{*}$ \\
\hline
\end{tabular}

\begin{tabular}{lccccc}
\hline \multicolumn{7}{l}{ Categorical Analysis } & & & \\
\hline State-level cultural sexism [range] & $K$ & Predicted $g$ & $S E$ & $95 \%$ CI & $\begin{array}{c}\text { Moderator } t \text { - } \\
\text { test }(t \text {-value) }\end{array}$ \\
\hline Low [-1.91, -.303] & 308 & 0.34 & .04 & {$[.27, .42]$} & $8.87^{* * *}$ \\
High [-0.3044, 1.90] & 232 & 0.20 & .03 & {$[.13, .26]$} & $5.96^{* * *}$ \\
\hline
\end{tabular}

Note: Predicted effect sizes (predicted g) are given at the low and high values observed in the data (i.e., above and below the mean). $k=$ number of effect sizes in each category (total $k=702$ derived from 95 studies with majority-girl samples). Results were produced using (1) random-effects meta-regression models excluding the intercept and including the "factor" function in the R metafor package, and (2) Knapp and Hartung adjusted t-tests (Viechtbauer, 2010). A significant moderator t-test result indicates that the effect for the cultural sexism level is significant after adjusting for the other level. Median household income was available from the US Census Current Population Survey and was pooled and averaged across all years 2000-2010.

$* p<.05, * * p<.01, * * * p<.001$ 